\title{
Dynamic Capabilities and Business Model Innovation of Platform Enterprise: A Case Study of DiDi Taxi
}

\author{
Ping Lin, ${ }^{1,2}$ Xiaosan Zhang, ${ }^{3}$ Shuming Yan $\mathbb{D},{ }^{1}$ and Qingquan Jiang $\mathbb{D}^{4}$ \\ ${ }^{1}$ Newhuadu Business School, Minjiang University, Fuzhou 350108, China \\ ${ }^{2}$ Research Center for Energy Economics and Low-Carbon Development, Minjiang University, Fuzhou 350108, China \\ ${ }^{3}$ Research Centre for Belt and Road Financial and Economic Development, Xiamen National Accounting Institute, \\ Xiamen 361005, China \\ ${ }^{4}$ School of Economics \& Management, Xiamen University of Technology, Xiamen 361024, China
}

Correspondence should be addressed to Shuming Yan; yanshuming@nbs.edu.cn and

Qingquan Jiang; jiangqingquan@xmut.edu.cn

Received 19 March 2020; Revised 24 June 2020; Accepted 30 June 2020; Published 17 July 2020

Academic Editor: Chenxi Huang

Copyright $\odot 2020$ Ping Lin et al. This is an open access article distributed under the Creative Commons Attribution License, which permits unrestricted use, distribution, and reproduction in any medium, provided the original work is properly cited.

\begin{abstract}
Internet has revolutionized business model and given birth to sharing economy. A large number of platform enterprises are growing rapidly but with sustainability problems. Platform enterprises have to continue innovating business models in order to obtain sustainable competitive advantages. In complex and varying environment, dynamic capabilities help enterprises overcome core rigidity and promote business model innovation. This article analyzes the elements of business model innovation of platform enterprises and also the relationship between dynamic capabilities and business model innovation. It concludes that the elements of business model innovation are value proposition, product, partnership, and profit model innovation. Dynamic capabilities promote business model innovation which has different guiding effects on the cultivation of dynamic capabilities. An exploratory case study was conducted, using DiDi taxi as an example, and verified the theory model.
\end{abstract}

\section{Introduction}

Internet has transformed trade locations, expanded trade exchange hour, enriched trade item varieties, accelerated trade speed, and reduced intermediaries. Internet has revolutionized previous business model and given birth to sharing economy. Many platform enterprises come into being, and many unicorn enterprises have been developed under the context of sharing economy. Sharing economy influenced at first transportation and housing industry; nowadays, it influences finance, delivery, lifestyle services, and technology industry. From consumption to production, sharing economy has played a role in every field and segment market. In some segment markets, hundreds of platform enterprises appear, grow in a fast pace within a very short amount of time, and eventually become competitive and representational enterprise. Advanced development of Internet technology has provided a solid foundation for platform enterprise's growth but, at the same time, led to brutal competition. Unfortunately, many platform enterprises flourished for only a few years before their decline and even closing-down. Therefore, it can be concluded that the innovation of business model is never once and for all. Under the dynamic and complex environment, enterprises must continue innovating business model to obtain sustainable competitive advantage.

Compared to traditional enterprise, platform enterprises face much more uncertainties, including faster-changing technology environment, lower entering barrier, and intense competition. What is worse, it is much easier to be imitated. On the one hand, the factors that lead to fast development include technology revolution, market globalization, uncertainty of consumer preferences, ever-changing industry, and institutional environment. On the other hand, the interaction between different factors makes the competitive environment more complicated. In order to become flexible 
and maintain competitive advantage in such dynamic environment, platform enterprise must foster dynamic capabilities to overcome core rigidity and innovate business model constantly. Therefore, it is necessary to combine dynamic capabilities with business model innovation.

As of now, although there is enormous research focused on dynamic capabilities as well as business model innovation, very few studies explore the intersection and interaction of the two. Meanwhile, there is also a lack of research on relationship between dynamic capabilities and business model innovation for platform enterprise. Therefore, this paper aims to analyze features of platform enterprise under Internet environment, using DiDi taxi as an example, to study how dynamic capabilities can promote business model innovation to obtain sustainable competitive advantage. It concludes that dynamic capabilities promote business model innovation which has different guiding effects on the cultivation of dynamic capabilities. The main contributions of this paper can be summarized in the following two aspects. First, this paper enriches the research of dynamic capabilities in the era of sharing economy. Second, this paper guides enterprises, especially platform enterprises, toward combining business model innovation with dynamic capabilities and taking various measures to ensure the success of business model innovation.

\section{Theoretical Analysis}

2.1. Business Model Innovation. Different scholars have different interpretations for the concept of business model. J. Magretta [1] believes that business model portrays a story of the enterprise that catches attention of investors. Rappa [2] believes that business model shows how the business operates fundamentally. Osterwalder et al. [3] believe that business model creates value for enterprise to maintain competitive advantages. Zott et al. [4] believe that business model describes the operation of the enterprise from a systematic and holistic perspective.

After analyzing and classifying more than thirty business models, Morris et al. [5] believe that business model can be defined by economy, operation, and strategy. Economic definition classifies business model as economy model. It suggests that business model defines how the enterprise generates profit, and the main factors include operational planning, financial and human resources process, risk management, and internal operation mechanism. Operational definition classifies business model as competitive and development strategy. Its main factors include product differentiation, enterprise vision, and cooperative partners. Strategy definition at first focused only on enterprise's internal profit model, product, and operation management and marketing strategy; nowadays, it focuses mainly on how the company benefits through seizing market opportunities and providing products to consumers. In the case of start-up companies, the business model is the profit model, since the enterprise could only create unique value by identifying consumers' urgent unsolved needs in the market. Although the current research results have not reached a unified understanding, most of them agree on the concept that business model explains how enterprises create value in a systematic and holistic perspective. This paper defines business model as an elaboration on enterprise's production and operation activities.

However, scholars' definitions of business model innovation are mainly based on the universal industries and do not concern the business model innovation of special industries with specific means or approaches. For different industries, the broad dimension of business model innovation is basically the same, but for the research on specific approaches under the broad dimension, there are few theoretical studies. From the industrial period to the current Internet period, decentralization and massive interaction between people, driven by Internet, have led to sharing economy. Sharing economy utilizes Internet and other information technology to integrate and share massive decentralized idle resources and satisfy the sum of economic activities, whose demands are diverse. With Internet as foundation, sharing economy stimulated the birth and growth of many platform enterprises. "Platform" is a vivid depiction: the platform enterprise does not produce any product or create any core value but connects core value creators and consumers. It simply creates a platform for service provider to serve consumers effectively. Throughout the process of creating the platform, platform enterprise develops from "trading platform" to "reliable platform" and then to "trusted platform." When "trading platform" carries out transaction effectively while having constructed qualification examination certification, management, and insurance, it turns into "reliable platform," which reduces transaction cost by a large amount. After establishing the reliable transaction relationships on the platform, participants develop emotional exchange and even spiritual exchange; therefore, "reliable platform" becomes "trusted platform." "Trusted platform" has a "magnetizing effect" on participants, facilitating communication and understanding between two sides of transaction while further promoting trade. For example, Alibaba started as a "trading platform" for consumers, but when it realized that consumers always worry about being deceived, it conducted qualification examination and background check before anyone enters the market, which helps in investigation when fraud occurs. Therefore, Alibaba has established a trust relationship with consumers by providing them with a safe and secure transaction platform. With more transaction, many participants start to communicate and share through the Internet; as a result, participants develop "trusted" relationship with each other. This paper defines platform enterprise as the enterprise which relies on Internet as the foundation, connects communication as well as multiple markets, realizes the integration of multiple industries, satisfies demands from a variety of groups, and profits from such action.

In the Internet period, platform enterprise's business model undergoes some great changes. Platforms link the supply and demand sides of the resource, so people buy products and services on a point to point basis rather than on the corporate basis. Both resource providers and resource demanders could participate in sharing economy at any time and from any place; as a result, larger scale and wider range of idle resources are shared. Enterprises and customers all 
become value creators, while products and services are not specifically produced but are instead derived from recycling of idle resources. All in all, the new characteristics of Internet platform enterprises promote the business model innovation. There are unique ways in business model innovation of platform enterprises.

\subsubsection{Customer Value Proposition Innovation. Customer} value proposition represents an in-depth description of the customer's real needs. It also represents a unique value that enterprises convey to users for them to understand and make a purchase of a product or service, and for the company to enhance brand loyalty. The traditional business model is mainly based on the core capabilities of the enterprise and it provides what it produces to the customers. Usually, the products or services are standardized with no adjustment or specialization to customer need or market change. Under the sharing economy, enterprises are no longer limited to products provided by enterprises. Any resource owner can share his unique idle resources on the platform at a lower price to provide more unique products for the demand side. As a result, a large number of personalized, diversified products can provide diverse experience for participants and satisfy deeper emotional needs of the users. At the same time, the sharing platform increases the variety of the transaction objects and the products, reduces the buyer's information asymmetry, and reduces the transaction cost between seller and buyer, thus improving the satisfaction and economic value of the two parties. There are two main ways for platform enterprises to innovate customer value. The first is to identify customer needs through in-depth research and analysis. The second is to create consumer demand. According to the spiritual needs and other intangible needs of consumers, enterprises find new interest points and seek consumers' recognition. For example, Uber's service is positioned as "Apple in taxi software," and its brand slogan, "your personal driver," has greatly enriched the customer's ride experience.

2.1.2. Product Innovation. Product is the connection between enterprise and consumer. When the consumer demand is found or created, the enterprise would present the customer value proposition with the product accordingly. Product innovation is to provide users with new products or better services through technological innovation, product design update, or service system improvement. One important prerequisite of platform enterprise is to have many users, and another is to have sticky service. Therefore, the products and services provided by the platform should constantly be enriched for the connection between the suppliers and the demanders to be more stable.

As more information can be searched by Baidu in China, users gradually equate search with Baidu, so more and more providers are willing to provide information on Baidu. Similarly, Alibaba relies on making it easier for users to find goods online, and Tencent specializes in connecting users with others to form a strong network effect. After the platform enterprise creates stable connection, there are two other prerequisites for further success. One is whether more and more different types of users can be pulled into the platform system through more products and services, and the other one is whether a transition from bilateral connections to multilateralism can be achieved. With more diverse participants, the platform tends to be stickier and more efficient and gradually develops into a huge ecosystem. Therefore, platform enterprises should pay special attention to product innovation to increase the quantity and stickiness of customers and meet the needs of customers.

2.1.3. Profit Model Innovation. The profit model refers to the income structure, cost structure, and corresponding target profits divided according to different stakeholders. Profit model innovation mainly includes cost control innovation and revenue mode innovation. The cost control innovation of traditional enterprises mainly focuses on large-scale production, outsourcing, acquisition, and other means. The innovation of income model focuses on increasing sales through enhancing publicity, improving service level, and carrying out the promotion activities. There are two main ways for platform enterprise to achieve cost innovation. The first one is to allow both sides to trade through shared platform, and reduce the transaction cost. The second is to "reuse" idle resources, which not only eliminates the production cost, but also improves the value of the product by repeated utilization with high efficiency. The revenue model innovation of platform enterprises mainly includes transaction profit, service charge, and advertisement fee. Transaction profit refers to the transaction commission based on a certain proportion of the supplier or the buyer's revenue. Service charge refers to charging the registered member for provided service. For example, some websites would provide movie or music downloading service for paid members. Advertisement fee establishes a good benefit sharing mechanism by charging of advertising fee from the third advertising parties based on the flow rate, instead of charging consumers directly. Baidu and Google's process of bidding for advertising serves as an example of advertisement fee.

\subsubsection{Cooperative Partnership Innovation. Cooperative} partnership refers to the long-term cooperative relationship of sharing information, sharing risks, and sharing interests between enterprises because of mutual trust, in order to achieve the common goals of both parties. The innovation of partners in traditional enterprises is mainly aimed at partners with no competitive relationship with the enterprise, such as the upstream suppliers and the downstream distributors, by means of strengthening the quality of the cooperative relationship, removing the useless cooperation relationship, or adjusting the mechanism of the cooperative relationship. And the partnership innovation of the platform enterprise focuses on finding the common interest with the third-party enterprises such as competitors and cross-border enterprises, transforming the competitive relationship into organic win-win cooperation, with each enterprise contributing its own resources, and maximizing the overall interests. Partner innovation can be achieved through 
screening potential partners or adjusting relationships with different partners, or through choosing a variety of cooperative ways, which include buying resources from third parties and developing jointly with the third party.

2.2. Dynamic Capabilities. Since the 1990s, the dynamic capabilities theory has been widely accepted by scholars. The dynamic capabilities theory is based on the resource-based view and capability theory. Both theories believe that the competitive advantage of the enterprise comes from the resource bundle and core competence of the enterprise. Teece [6] proposed the dynamic capabilities as the abilities to build, reset, and integrate the internal and external resources in order to cope with the fast-changing environment, to maintain the competitive advantage. Teece [7] integrates the abilities to perceive and grasp opportunities into the connotation of dynamic abilities. When studying the microcosmic foundation of dynamic capabilities, he proposes that such capabilities refer to the abilities to perceive, create, and seize opportunities and to combine, strengthen, protect, and even reconstruct internal and external resources to maintain the competitive advantage. Other scholars regard dynamic capabilities as a convention, process, and pattern. Zollo \& Winter [8] define a dynamic capability as a learned and stable pattern of collective activity through which the organization systematically generates and modifies its operating routines in pursuit of improved effectiveness.

At present, scholars have not reached consensus on the dimension of dynamic capabilities. While Teece et al.[6] make it clear that dynamic capabilities are composed of three dimensions of integration, construction, and reconstruction, Wang \& Ahmed [9] point out that dynamic capabilities consist of three parts: absorption, adaptation, and innovation. Absorptive capacity refers to the absorbing external knowledge and integrates it into internal knowledge; adaptability emphasizes the matching of the internal elements of enterprises and the external environment; innovation ability refers to the way enterprises rely on internal innovation to obtain market advantages. Teece et al. [10] point out that dynamic capabilities include not only the ability to integrate and reconfigure resources, but also the cognitive dimension, that is, to perceive and identify opportunities and threats. The reason is that when facing a rapidly changing global environment, enterprises could maintain competitive advantage only through responding to opportunities and threats in time. On the other hand, Pavlou \& Eisawy [11] and Lin [12] define dynamic capabilities as perception, learning, coordination, and integration capabilities.

Sorting the above literature, this paper finds that the research on dynamic capability is universal. Less attention is paid to the dynamic capability of a specific industry. The environment of the Internet age is full of uncertainties. Accordingly, the management of enterprises is also highly uncertain. The most important thing for the platform enterprise is continuously integrating and restructuring resources and capabilities to maintain current updates. Accordingly, dynamic capability is not only the integration of internal resource, but also the integration of internal and external resources of enterprises. This paper defines dynamic capabilities as the ability to identify and seize market opportunities and integrate the internal and external resources in order to cope with the changing external environment and sustain competitive advantages. The dimensions of dynamic capabilities of platform enterprises are market perception capability, learning and integration capability, coordination capability, and organizational flexibility, and the emphasis of each capability of platform enterprise is different from that of traditional enterprise.

2.2.1. Market Perception Capability. With the industrial economy, manufacturers create value through a series of activities within the value chain. However, in the era of Internet, customers are the source of value creation and part of value creation. The sharing platform creates the conditions for the user to communicate and share in a socialized way. A public and transparent evaluation system is set up between the suppliers and the consumers, and the consumers can also check the product reviews by other consumers at any time before making a purchase decision. Consumers pay more attention to personalized needs and focus more on the product experience, as well as social, leisure, emotional, and other deeper aspects of the experiences. And more consumers take the initiative to participate in the design and research of products. For example, Xiaomi, mobile phone company, will have the users vote in the forum every Friday to determine the direction of research and development; the forum has about more than a million visits per day and there are nearly 300 thousand posts overall. Users of Xiaomi are deeply involved in company's research and development, and vice president Li Wanqiang has said that Xiaomi's purpose is not selling products, but creating a sense of participation. Moraes [13] believes that value is derived from the experience brought to the customer. On the other hand, Gourville [14] believes that value is driven by thoughts of the customer, and they create value and share value with the enterprise.

Therefore, for the platform enterprise, it is very important to have market perception capability, which equips the enterprise with ability to quickly interpret the changes of government or industry policies, grasp the latest trends of competitors, see the demand of consumers for frequent changes, and find the new market opportunities more efficiently and quickly. Moreover, the technology entering barrier of Internet enterprises is low, easy to imitate, and full of uncertainty. Consequently, a good business idea would be produced by dozens of similar enterprises at the same time, which all compete for customer resources. In each vertical segment, there is only one or two leaders, and the third one is easily bought out or goes bankrupt eventually. Therefore, many companies attract consumers quickly by burning money to capture the market share. All in all, it is crucial for platform enterprise to have strong market perception capability.

2.2.2. Learning and Integration Capability. Learning and integration capability refers to the ability of an enterprise to restructure and integrate internal and external resources in 
order to respond to environment changes. When the enterprise identifies the new market opportunities in the external environment and defines the innovation of the business model, it should redeploy and reintegrate the resources, by promoting exchanges and cooperation between the marketing, sales, $R \& D$, administration department, etc. It should first determine whether its own resources are enough to ensure the development and implementation of the new products. Next, if the internal resources are insufficient, the enterprise should introduce external resources through the means of learning, cooperation, and purchase. It is crucial for the enterprise to internalize the new resources and integrate them with the internal resources, including very specific knowledge like stakeholders' rights, the customer, the employees, and cross-border, internalizing external knowledge into organizational knowledge. The integration matches the enterprise' resources with its new desired strategic position and strives to maintain enterprise's leading competitiveness.

2.2.3. Coordination Capability. Coordination capability refers to the ability to coordinate with investment institutions, suppliers, advertisers, competitors, cross-border enterprises, and so on. In the Internet age, cooperation capability not only improves the product's adaptability, but also transforms the competitive relationship into a cooperative relationship strategically, making many unrelated and incompatible elements connected to create new values. Therefore, it is important for enterprise to coordinate the relationship between the stakeholders, such as competitors and partners, in order to share qualified resources, cooperate in the competition, and compete in cooperation. The coordination capability includes the ability to select highquality cooperative partner, to establish and maintain a good lasting relationship with stakeholders, to bargain effectively, and to construct a considerable interest sharing mechanism.

2.2.4. Organizational Flexibility. In this process of change, the corporation has to prevent itself from overshooting and becoming extremely rigid or chaotic. Enterprise that has organizational flexibility reacts to changes effectively by restructuring the business process, organization structure, communication system, and management system. In the Internet economy, learning organization, information sharing cloud platform, and network organization help to improve the organizational flexibility greatly.

\subsection{Relationship between Platform Enterprises' Dynamic} Capabilities and Business Model Innovation. Now the research on the formation mechanism of dynamic capability is still limited. This paper chooses business model innovation as the starting point of dynamic capability cultivation and discusses the relationship between business model innovation and dynamic capability.

Firstly, in a dynamic environment, the dynamic capabilities of platform enterprises can effectively promote the successful implementation of business model innovation
(Najmaei) [15]. For example, the market perception ability can monitor the external environment in real time, grasp the changes in consumer demand, interpret the changes in government or industry policies, grasp the latest trends of the competitors, better satisfy the consumer needs, and find new market opportunities more efficiently and faster than the competitors. This promotes customer value proposition innovation. The integration ability allows enterprise to absorb external knowledge, transform it into internal knowledge, and reorganize and integrate all resources in time to ensure the quality and speed of product development, thus promoting product innovation. The coordination ability is favourable for the platform enterprises to establish good sharing mechanism with the stakeholders, to increase the income source and proportion, and to match the strategic positioning with own resources, thus promoting the income model innovation. Teece [16] mentioned that the strength of a firm's dynamic capabilities helps to shape its proficiency at business model design. Through its effect on organization design, a business model influences the firm's dynamic capabilities and places bounds on the feasibility of strategies. Organizational flexibility adjusts the organizational structure and functional modules according to the dynamic changes of the external environment to respond to the needs of customers fast and flexibly and to promote partnership innovation.

Secondly, platform enterprises choose feasible and new business models according to the change of dynamic capabilities. Warner and Wager [17] proposed a process model with nine micro foundations to reveal the generic contingency factors that can trigger, enable, and hinder the building of dynamic capabilities for digital transformation, revealing that agility is the core mechanism for the strategic renewal of an organization's business model. Business model innovation can be based on the original business model, or also a completely new business model. When the new type of business model is selected, the platform enterprise should determine whether its own capabilities and resources can support the success of the new business model. If the new model can be supported, the platform enterprise will rely on the existing capabilities and resources to carry out the business model innovation. If not, the platform enterprise must first develop its own dynamic capabilities. When the new dynamic capabilities are formed, the enterprise can effectively promote the successful implementation of business model innovation, thus obtaining the leading competitive advantage.

Finally, the different paths of business model innovation have different guiding effects on the cultivation of dynamic capabilities. If the new dynamic capabilities are still unable to provide effective support, it is necessary for the enterprise to revise the cultivation measures of the dynamic capabilities and to carry out a new round of cultivation. Therefore, in order to maintain the leading competitive advantage, platform enterprise has formed an internal dynamic cycle to cultivate dynamic capabilities of leading business model innovation (Figure 1).

In addition, business model innovation cannot be successful with only one try. In order to maintain competitive 


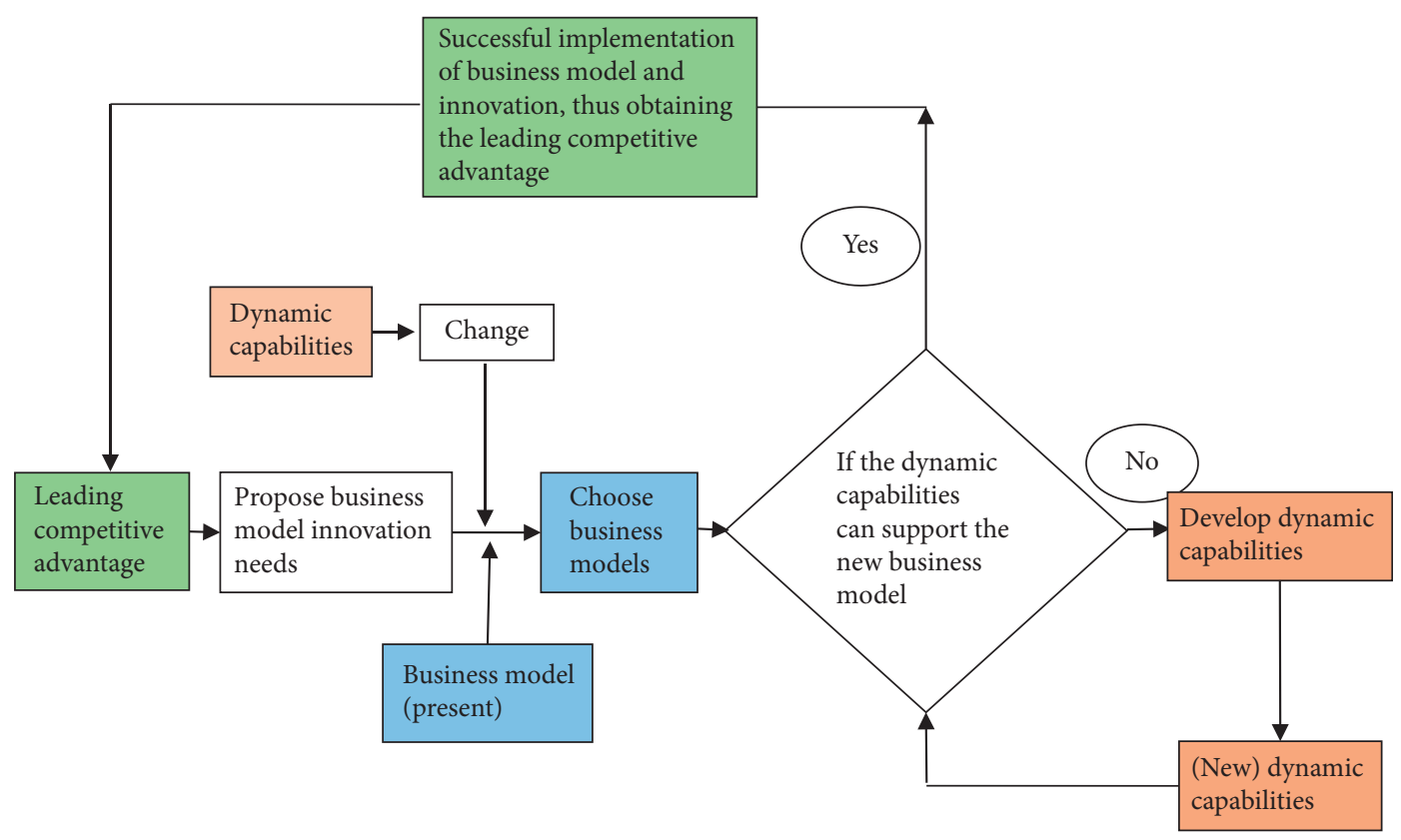

FIgURE 1: The relationship between platform enterprises' dynamic capabilities and business mode innovation.

advantage in a turbulent environment, enterprises are constantly making use of dynamic capabilities to continue to innovate business model. After the cultivation of the platform enterprise dynamic capabilities (present) is achieved, the dynamic capabilities (New 1) can identify the new changes, reorganize the various resources of the enterprise, and promote a new round of business model (New 1) innovation. Therefore, there is a dynamic cycle between the cultivation of dynamic capabilities of platform enterprises and business model innovation (Figure 2). In this process, business models are continuously innovated, and dynamic capabilities of platform enterprises are continuously improved.

\section{Research Design}

3.1. Selection of Research Methods. This study takes an exploratory single case study as example. First, it explores the business model innovation of the platform enterprise and the role of dynamic capabilities under the Internet environment. There is few specific answers in the existing literature or publications. A case study allows the investigation of a phenomenon in the real-life setting, so it is suitable for this research to adopt the case study method. Second, indepth description and analysis of specific phenomena are helpful to understand the dynamic and complex mechanism behind a phenomenon. Eisenhardt and Graebner [18] point out that case study is a very objective and rigorous empirical method that is close to reality. They introduced two different methods of case analysis in detail: phenomenon driven and theory driven case analysis methods. The phenomenon driven type strives to establish the theory from the phenomenon and is applicable to situations where there is no feasible theory. The theory driven type is based on the existing theory to establish the framework and to discover the qualitative data for verifying and developing the theory. This research paper adopts the theory driven case study method.

In order to verify and expand the theory, researchers often choose extreme and enlightening cases that satisfy theoretical requirements. Such cases help to exclude the interference of research factors in the typical situation, so that the researchers can observe and analyze the more valuable scientific phenomena and make the research conclusions more powerful. Therefore, this study chooses $\mathrm{DiDi}$ taxi (also referred to as $\mathrm{DiDi}$ ) as a case study. There are three main selection criteria: Firstly, DiDi has been set up only 6 years ago and has become the largest station mobile travel platform in the world. Secondly, DiDi is a new model of "Internet plus traditional industry." Its business model innovation practices the typical characteristics of the idea of sharing economy under the Internet environment, and it is helpful to analyze the relationship model between the platform enterprise's dynamic capabilities and the business model innovation. Finally, DiDi is facing rapidly changing dynamic environment. Specifically, great changes, regularized and coordinated by government and transportation authorities, have been made in the industry policy environment. The market competition has become much fiercer due to competitors employing other business models or other service providers like shared bicycle platform, while consumers' preferences are always changing.

3.2. Case Introduction. DiDi business includes taxis, special cars, express cars, and buses, getting through the $\mathrm{O} 2 \mathrm{O}$ closed loop. Since its inception in 2012, DiDi has served more than 400 domestic cities to meet 300 million of the travel demands of consumers. In 2015, DiDi's online platform completed a total of 1.43 billion orders, making DiDi China's second largest online trading platform after the top one 


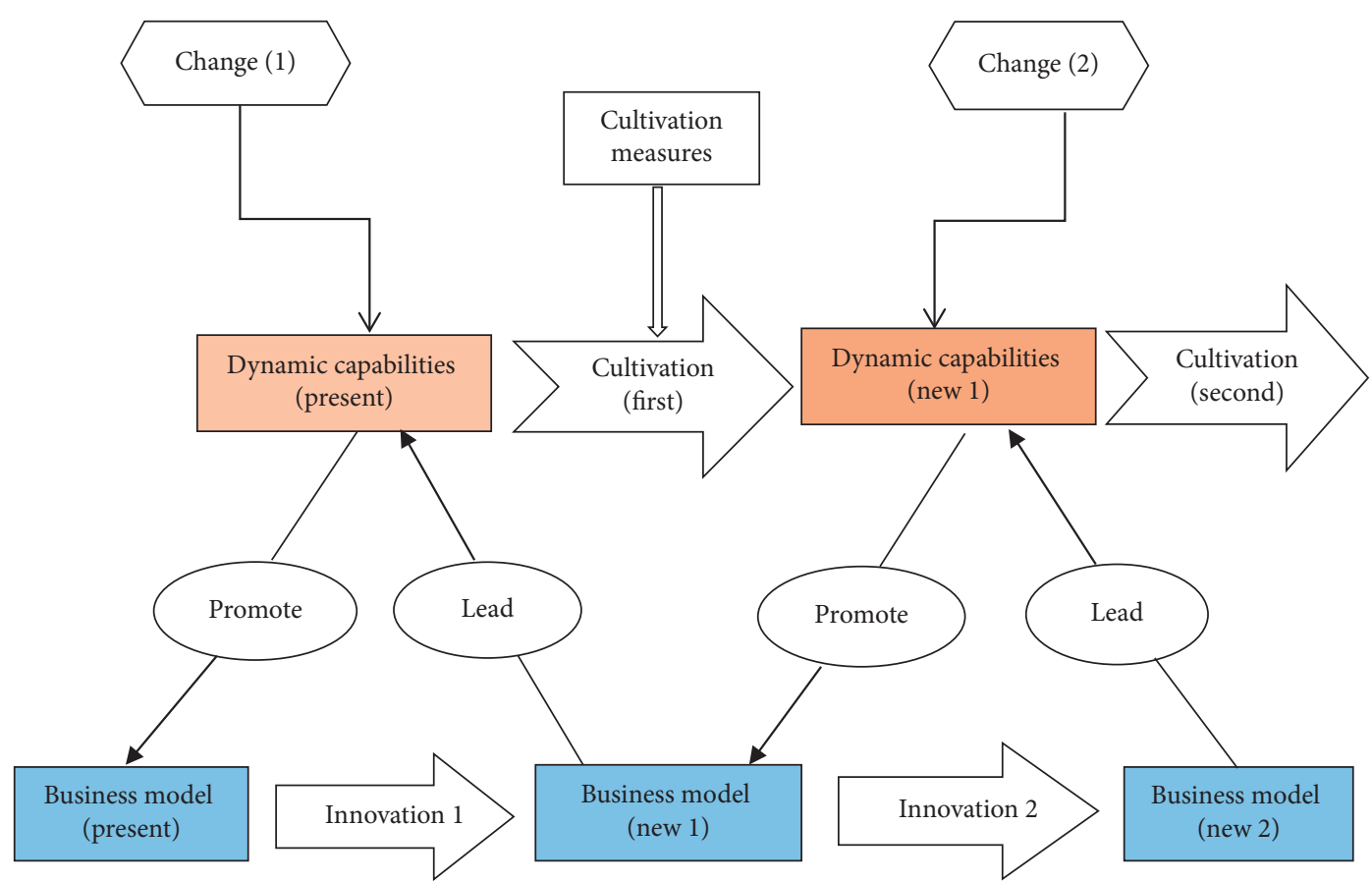

FIgURE 2: Dynamic cycle between the cultivation of dynamic capabilities and business model innovation.

Taobao. Its valuation in 2017 has exceeded $\$ 16.5$ billion with more than 200 million users, accounting for more than $87 \%$ of the domestic car market and $99 \%$ of the online taxi market. The course of its development is shown in Table 1.

3.2.1. Phase 1: Market Cultivation Period. During this period, DiDi's overall growth slowed, but it eventually overcame the biggest challenge by introducing a new-brand platform product which operates with a difficult product logic to cultivate users and products. Since its establishment on July 10, 2012, DiDi developed better product and service to expand its market service for driver side and customer side. On October 28, 2012, version 1.1, following a new version of iOS, supported the new Apple system more efficiently. Moreover, it added instant messaging to the arrival of a taxi, a one button duplication function, and a simplified registration process. On December 2, 2012, version 1.2 introduced three new functions. The first one was the appointment function, which allowed users to make an appointment for the next day or even the day after it. The second was the "increased price" function: during the peak of taxi demand, it offered "increased price" for the users to enhance their success rate in getting a taxi. Last, this version also simplified the registration and landing process, so both drivers and users benefit from the convenience. On December 18, 2012, version 1.3 introduced "call-waiting function," which allowed extending the peak waiting time and was expected to raise the call success rate by $40 \%$. This version also optimized the start speed of the software.

In 2013, from version 1.4 to 2.5 , DiDi experienced many new changes. It added "instant calling" and "appointment from different cities" function. It also introduced many new functions including V2.1 sound effect, friends invite, taxi- hailing tips, presaved home and company address, order canceling, custom location, tip adjustment, and flexible reservation time. At this stage, DiDi solved the situation where a significant number of people cannot get the taxi by creating the car-hailing platform with millions of users. It has provided a real value for hundreds of thousands of people enabling them to travel more efficiently. In October 2013, iResearch Global (China) released the only industry report on taxi software: DiDi's market share was $59.4 \%$, exceeding the market share of the other taxi software combined. DiDi's growth was mainly driven by stable market operations (vigorously advancement and multiparty cooperation), as well as constant product improvement.

3.2.2. Phase 2: Accelerated Growth Period. From January to September 2014, the number of DiDi users increased significantly. After completing the transformation from being an available travel tool to a common travel tool, DiDi acquired a larger market share. In 2014, the market competition became fierce and the growth of user base in taxi applications increased rapidly. In the face of powerful competitors like "KuaiDi," the focus of DiDi was on rapid user growth. DiDi succeeded through subsidies and cooperation with WeChat. In January 2014, DiDi reached a strategic cooperation with WeChat to open WeChat payment, making it much convenient for users to pay. $\mathrm{DiDi}$ also incorporated red pocket subsidy and even provided free rides. At this stage, DiDi and KuaiDi invested a total of about 2 billion yuan of market subsidies, in order to cultivate a larger market and develop the user's habit of using the software. In March 2014, the number of DiDi users exceeded 100 million and the number of drivers exceeded 1 million, 
TABle 1: The course of DiDi's development.

\begin{tabular}{|c|c|c|}
\hline Phase & Time & Product \\
\hline $\begin{array}{l}\text { (1) Market cultivation } \\
\text { period }\end{array}$ & $2012.09-2012.12$ & $\begin{array}{l}\text { V1.0: setting online; V1.1, V1.2: online appointment, increased price, simplifying the } \\
\text { registration and landing process; V1.3: call-waiting function, extending the peak waiting time } \\
\text { V1.4, V2.0: instant calling, appointment from different cities; V2.1: sound effect, friends invite, } \\
\text { taxi-hailing tips; V2.2: presaved home and company address; V2.3, V2.4: order canceling, } \\
\text { custom location, tip adjustment; V2.5: flexible reservation time }\end{array}$ \\
\hline $\begin{array}{l}\text { (2) Accelerated growth } \\
\text { period }\end{array}$ & 2014.01-2014.08 & V2.6: WeChat payment; V2.7: free rides; V2.8: order deletion, optimizing the map \\
\hline (3) Rapid growth period & 2014.09-2015.02 & $\begin{array}{l}\text { V3.1: special car; V3.2: priority text "call"; V3.3: integral mall; V3.4: reservation car, subtype } \\
\text { recommendation, estimate cost; V3.5: new recommended award columns; V3.6: default ticket } \\
\text { for payment, new game center }\end{array}$ \\
\hline (4) Integration period & 2015.02- & $\begin{array}{c}\text { V3.7: pay hitching; V3.9: new express, driving agent, possibility of locating all cars at home and } \\
\text { company, Alipay, QQ wallet payment, driving service, automatic fare increase system; V4.1: } \\
\text { blacklist, making an appointment } 7 \text { days in advance, account reminding, chartered car, } \\
\text { investment sharing bicycle platform Ofo, car rental, overseas car rental business, artificial } \\
\text { intelligence laboratory, driverless car }\end{array}$ \\
\hline
\end{tabular}

with average daily orders of 5.2183 million, making DiDi the largest daily order trading platform on the mobile Internet.

3.2.3. Phase 3: Rapid Growth Period. From September 2014 to February 2015, the number of users increased rapidly, with 5 -time increase in half a year. In September, DiDi introduced "special car," which helped in its transition from the deep ploughing stock market to the beginning of the development of the incremental market. A series of optimization initiatives were introduced for the "special" user experience, such as subtype recommendation, estimate cost, default payment selection, and priority text "call." Through this series of initiatives, DiDi significantly improved the user's experience and trained a number of users to use the "special car" through the operation level, with aids like subsidy.

3.2.4. Phase 4: Integration Period of Resource Development. Since February 2015, DiDi has begun to diversify its development, aiming at all the subdivision areas of the travel industry and integrating travel resources to create a one-stop mobile travel platform. As the market became mature and saturated, the growth of users was slow and sustained subsidies were no longer a good means. Moreover, the impact of a powerful competitor was more and more significant, like Uber China. In February 2015, DiDi announced its merger with KuaiDi to nurture a bigger market. Since then, a series of services, such as express, pay hitching, bus, and driving agent, have been put online in an all-round way. DiDi became a "one-stop travel platform" for users. The service line of express and pay hitching service targeted the common users, while the special car targeted the middle to high end users. The function of the express car is foundation for the system of "combined carpool." In the future, it can be used by people in the lowest part of society, when the service of the carpool can make the car be users' "bus."

3.3. Data Collection and Analysis. This research strives to use a variety of sources to collect data, mainly including the following channels: (1) enterprise archives, such as enterprise journals, work summaries, internal rules and regulations, and enterprise annual reports; (2) official website of $\mathrm{DiDi}$; (3) media reports; (4) publications of thirdparty research institutions. Data sources and codes are shown in Table 2.

3.4. Construction Measure and Data Coding. The understanding of key constructs is based on the cross test of the research members and the use of charts for cooperation. Through continuous data analysis and data conceptualization, the logical relationship gradually emerges, and the theory is finally saturated. The measuring dimensions of key constructs are shown in Table 3.

Data were coded in a double-blind way. After encoding the collected material into concepts, the researchers classified the concepts and assigned them to the related existing concepts. Before the formal coding began, the coders involved conducted precoding and compared the results of the coding to test the encoders' understanding of the connotations and dimensions of the study. If the consistency rate of the coding results was more than $90 \%$, the coding process could be formally started. Data coming from the same source with similar meaning was recorded as one item. The results of the coding were presented in a tabular way. After the double-blind coding was completed, the two groups of encoders checked the coded results together. For the incompatible results, the two parties were asked to discuss them and reach a final agreement on the coding results.

This paper analyzes the business model innovation and dynamic capabilities of case enterprises and verifies the suggested theoretical model.

\section{Case Findings}

\subsection{DiDi’s Business Model Innovation}

4.1.1. Customer Value Proposition Innovation. DiDi is acutely aware of the changes in the market environment of the mobile Internet technology and the development of big data. With the help of the $\mathrm{O} 2 \mathrm{O}$ platform, a large number of 
TABLE 2: Data sources and codes.

\begin{tabular}{lc}
\hline Source & Code \\
\hline Enterprise archives & F1 \\
Official website of DiDi & F2 \\
Media reports & F3 \\
Publications of third-party research institutions & F4 \\
\hline
\end{tabular}

redundant resources and services in the society are linked with the needs by lease or purchase, so that the value of idle resources would be recreated, the utilization rate would increase, and the economic mutual benefit would be achieved. On the other hand, enterprises gain profits to support daily operations and win long-term development. The following is performed:

(1) Integrating Redundant Resources. all kinds of idle resources from private individual, car rental companies and taxi companies are integrated through the platform, and then vehicles or related services are provided to the groups in need.

(2) Improving Operation Efficiency. the advantages of the mobile Internet technology and the mining of large data are used to locate and match the supply and demand, effectively reducing the information asymmetry between the supply and demand and greatly improving the travel efficiency.

(3) Paying Attention to Service Experience. the scoring mechanism between driver and passenger is implemented, using the cloud computing and big data technology to divide drivers and passengers based on their scores, providing different service for different grades of drivers and users, and eliminating the phenomenon of "bad money driving out good money" as much as possible.

(4) Advocating Sharing Economy. a flexible, alternative way of work that can be done any time and, more importantly, with low barrier of entry is provided.

4.1.2. Product Innovation. DiDi is keenly aware of the personalized needs of Internet users in a sharing economy. It has carried out a series of product iterations to meet the needs of the market and user growth. With the convenience of data collection provided by its products, DiDi has been collecting feedback from consumers and constantly promoting functional optimization.

In the market incubation period, DiDi found out that, from the user reviews, the problem in V1.1 version is that passengers cannot register or cannot get a car. The fundamental reason of not getting a car was that there were very few DiDi drivers, thus leading to an uneven supply and demand. After introducing the appointment function, DiDi enabled users to find good cars ahead of time while increasing drivers' enthusiasm through increasing price and facilitating transactions. DiDi also solved the registration issue by canceling the registration process. In the period of accelerated growth, when facing strong competitors, DiDi cooperated with WeChat by introducing the WeChat payment function, replacing cash payment and starting a large-scale subsidy of red packet. In this stage, the product became much more well-rounded. In the rapid growth period, DiDi also launched the key product "special car" and had a series of optimization initiatives on the user experience and overall function. Based on different users' attitudes to travel service, type of the vehicle, price, and conveniency, DiDi developed corresponding products for different market segments and launched different travel services to meet personalized needs, like new model recommendation. Consumers could therefore choose vehicle type and grade according to their own consumption level, estimate cost, reservation call, default payment selection, and driver evaluation. During business integration period, based on the understanding of business and users, product version management became more refined with continuous iteration and optimization, as well as the launch of a series of products, such as express car and express bus. A one-stop mobile travel platform was created successfully.

4.1.3. Profit Model Innovation. Traditional manufacturing industries gain profits by selling products, while platform enterprises like DiDi make profit mainly from transaction costs, traffic advertising, service fees, third-party fees, and financial value.

(1) Transaction Costs. DiDi charges drivers 0.5 yuan per transaction fee, plus $1.77 \%$ management fees, as well as the revenue sharing with competitors, industry agencies, and third-party enterprises.

(2) Information Service Fee. Information service fee is collected from the passenger and the driver, respectively. In remote areas, bad weather, or busy time, the passengers and taxi drivers can choose to pay the information service fee of 0.5-2 times per single price and obtain the right to receive priority.

(3) Advertising Revenue. The peak of the daily trading volume of the platform reaches about 14000000 , and the DiDi charges the third-party partners by charging the traffic according to the flow rate, which will produce considerable advertising revenue.

(4) The Financial Value of a Huge Pool of Capital. DiDi pays its drivers every Tuesday, so that the company has a stable cash pool for 7 days. According to DiDi statistics, the peak of the trading volume reaches 14000000 orders per single day. In 2015, there were 1 billion 430 million order transactions. Thus, the drop trip would have great financial value for the huge pool of capital.

(5) The Value of Information Supported by Big Data. When the user uses DiDi, the software will record the location of the car and the passenger information and can get a point map similar to the commercial map through data analysis. DiDi covers more than 400 cities, with more than 300 
TABLE 3: Constructs and codes.

\begin{tabular}{|c|c|}
\hline Constructs & Codes \\
\hline $\begin{array}{l}\text { Customer value proposition } \\
\text { innovation }\end{array}$ & $\begin{array}{c}\text { Enterprises clearly understand the target customers and explore customer needs through innovative } \\
\text { ways }\end{array}$ \\
\hline Product innovation & Product iteration, technical innovation, changing product design, or improving service system \\
\hline Profit model innovation & Income structure and profit model are novel \\
\hline $\begin{array}{l}\text { Cooperative partnership } \\
\text { innovation }\end{array}$ & $\begin{array}{c}\text { Emphasizing win-win cooperation, developing cooperative networks in an innovative way, and } \\
\text { constantly introducing diversified partners }\end{array}$ \\
\hline Market perception capability & $\begin{array}{l}\text { Keeping abreast of customer needs and trends, making accurate predictions of technology trends in the } \\
\text { industry, keeping abreast of closely related policies, discovering and taping new market opportunities } \\
\text { more efficiently and quickly than competitors }\end{array}$ \\
\hline $\begin{array}{l}\text { Learning and integration } \\
\text { capability }\end{array}$ & $\begin{array}{l}\text { Updating outdated knowledge in real time; quickly learning knowledge from the internal organization, } \\
\text { suppliers, and competitors; introducing external resources by means of learning, cooperation, } \\
\text { purchasing, and other means to integrate internal and external resources; applying new knowledge to } \\
\text { new products }\end{array}$ \\
\hline Coordination capability & $\begin{array}{c}\text { Coordinating and cooperating with investment institutions, suppliers, advertisers, competitors, cross- } \\
\text { border enterprises, etc. }\end{array}$ \\
\hline Organizational flexibility & $\begin{array}{l}\text { Flexibility in organizational structure, communication systems, management systems, procedures, and } \\
\text { methods }\end{array}$ \\
\hline
\end{tabular}

million users. The detailed data have great informational value for the commercial distribution of real estate and urban construction of municipal construction departments for the improvement of traffic, and also for the consumer travel planning suppliers.

4.1.4. Partner Innovation. DiDi cooperates not only with enterprises in the industry and third-party enterprises, but also with its competitors through innovation, as follows.

(1) Enterprise Cooperation in the Industry. DiDi cooperated with agencies, travel companies, bus groups, etc. Also, it cooperated with automobile manufacturers and after-sales service providers. This shows that platform enterprises pay special attention to seeking common interests with thirdparty enterprises. Through such cooperation, each party contributes its own resources and creates greater value in accordance with a certain benefit distribution mechanism.

(2) Cross-Border Cooperation. DiDi cooperated with WeChat, Alipay, and other mobile payment platforms to facilitate user payment; with Baidu and Auto Navy Map to achieve precise location; with Qunar.com to add the function that allowed passengers to make online reservation from a different city; with Tencent, Lenovo, Dell, Jingdong, and other hundreds of enterprises for cross-border cooperation. It also worked with Jiangsu TV channel and WeChat platform to launch the largest red enveloped campaign in 2015 , which greatly stimulated consumption. It cooperated with many other high-quality media platforms such as Ali travel and Hunan TV channel to start a harmonious marketing campaign and with service platforms such as Home Inn and Auto Navy Map.

(3) Cooperation with Competitors. DiDi acquired KuaiDi, Uber, and other competitors in the industry to avoid vicious competition and achieved the integration of useful resources and the growth of overall value. The implementation of differential operation and the integration with the traditional taxis, which helped taxis to carry out online management and technological dispatch, avoided the conflicts caused by alternative competition and improved their operation efficiency overall.

All in all, through these measures, DiDi embodies not only the uniqueness of platform enterprise's business model innovation but also the platform enterprise's priority on transforming the competitive relationship into organic winwin cooperation and achieving the maximization of the overall interest.

\subsection{Relationship between Dynamic Capabilities and Business} Model Innovation. Business model innovation elements and corresponding dynamic capabilities from the case are shown in Table 4.

First, dynamic capabilities promote business model innovation. DiDi constantly cultivates its dynamic capabilities, which promotes and guarantees the success of business model innovation, so that enterprises can obtain sustainable competitive advantages.

Market perception capability promotes customer value proposition innovation. Market perception is the ability of enterprises to discover and seize market opportunities and avoid all kinds of external threats. Customer value proposition is an in-depth description of the real needs of customers. Every DiDi's customer value proposition innovation benefits from its market perception ability. DiDi pays special attention to customer evaluation, listens to consumers' opinions, and realizes Internet user's personalized, diversified, experiential, and deeper emotional needs. Therefore, it quickly sees and seizes market opportunities. In time, it formulates corresponding measures according to the changes in government related policies, competitors' trend, and customer requirements. With the help of the Internet technology, as well as the precise user needs as guidance, it sets the specific user experience as the promotion target and continues to look for new interest demand points, such as 
TABLE 4: The list of business model innovation elements and dynamic capabilities.

\begin{tabular}{|c|c|c|}
\hline $\begin{array}{l}\text { Business model } \\
\text { innovation }\end{array}$ & Form & Dynamic capabilities \\
\hline $\begin{array}{l}\text { Customer value } \\
\text { proposition } \\
\text { innovation }\end{array}$ & $\begin{array}{l}\text { Integrating redundant resources through the platform; } \\
\text { using large data mining to improve operational } \\
\text { efficiency: providing differential services for different } \\
\text { levels of drivers and passengers to improve service } \\
\text { experience; and advocating a sharing economy }\end{array}$ & $\begin{array}{l}\text { Market perception capability: listening to customers' } \\
\text { opinions, focusing on customer evaluation, and detecting } \\
\text { changes in external environment }\end{array}$ \\
\hline
\end{tabular}

Learning and integration capabilities: improving the poorly evaluated products, obtaining new knowledge A series of products, such as taxi, DiDi special car, and from the external environment, such as consumers, express have been iterated, and the service system of the competitors, and partners, integrating them into internal car under the support of big data has been established, knowledge, and ensuring the speed of product iteration which has formed a higher trade barrier

Organizational flexibility: quickly responding to customer needs, adjusting organizational structure and only module

Profit model
innovation $\begin{gathered}\text { The proportion of orders fee, information service fees, } \\ \text { advertising revenue, the financial value of large pools, } \\ \text { and the information value of big data }\end{gathered}$

Partnership with WeChat, Alipay, and other mobile payment platforms; partnership with Micro-Blog, the Front, Ali Travel, Hunan Satellite TV, and other media platforms; partnership with the GAD map, Home Inn, and other living service platforms

Partnership innovation

\begin{abstract}
Merger with competitors in the industry, such as the KuaiDi, integration with the traditional cruising taxi, cooperation with the tourist company, the bus group, the automobile manufacturer, the service provider of the auto after-sale service, and so on
\end{abstract}

Coordination capability: finding common interests with competitors and cross-border enterprises and turning the competitive relationship into organic win-win cooperation

Coordination capability: good relationship with Tencent, Alibaba, Sina, Auto Navy Map, and other cross-border enterprises, as well as good negotiation and communication skills

Coordination capability: Good relationship with competitors, taxis, and upstream and downstream companies such as the after-sales market, as well as negotiation and communication skills
WeChat payment and special car. By doing so, DiDi achieves consumer's approval and promotes the innovative customer value proposition rapidly.

Learning and integration capabilities promote product innovation. Learning and integration mean the ability of enterprises to integrate new knowledge with old knowledge and effectively combine internal and external resources, on the basis of receiving and digesting new information. After identifying external environment changes and market opportunities, DiDi focuses on customer evaluation, especially bad reviews, and continues to obtain useful information and identify beneficial resources and opportunities from consumers, competitors, suppliers, partners, and other external markets, effectively translating the new information into the internal knowledge. Moreover, DiDi explores beneficial new knowledge that would be beneficial for product improvement, firm internal operation, and future development and improves firm's ability to adapt to external change. In addition, DiDi internalizes external resources in time while constantly adjusting the business model and updating existing products and services. By doing so, DiDi ensures the speed of product iteration and establishes strategic barriers so that competitors cannot easily obtain the same speed and quality of product development, even though they have the same resources.

Coordination capability promotes profit model and partner innovation. DiDi focuses on finding interests in the third-party enterprises such as competitors and cross-border enterprises, transforming the competitive relationship into organic win-win cooperation. Each subject contributes its own resources and maximizes the overall interests according to a certain benefit distribution mechanism.

Organizational flexibility promotes product innovation. In the dynamic external environment, DiDi's organizational flexibility is manifested by customer evaluation and the fast adjustment done by the sales, marketing, $\mathrm{R} \& \mathrm{D}$, and organizational administration and functional modules basis. Such fast and elastic changes can respond to customer needs in time and promote product creation.

Then, business model innovation has different guiding effects on the cultivation of dynamic capabilities. In the past 6 years, the business model innovation of $\mathrm{DiDi}$ was not a single event. There have been many business model innovations every year. It also requires that $\mathrm{DiDi}$ constantly cultivates corresponding dynamic capabilities, which in turn promote and guarantee the success of business model innovation, so that enterprises can obtain sustainable competitive advantages.

\section{Conclusion}

With the rapid development of Internet technology, the number of platform enterprises increased significantly, and many unicorn enterprises have been developed. Platform enterprises are quite different from traditional manufacturing industries in terms of production cost structure, trading pattern, profit mode, and consumer consumption habits. Under the dynamic environment, the company must make strategic adjustment which means that the company should undertake business model innovation. Most previous research 
about dynamic capabilities mainly focused on content and composition and ignored the relationship between dynamic capabilities and business model innovation.

Based on the previous literature, this paper shows that the elements of business model innovation of platform enterprise are value proposition innovation, product innovation, partnership innovation, and profit model innovation. The dimensions of dynamic capabilities of platform enterprises are market perception capability, learning and integration capability, coordination capability, and organizational flexibility. Dynamic capabilities promote business model innovation which has different guiding effects on the cultivation of dynamic capabilities. An exploratory case study was conducted, using $\mathrm{DiDi}$ taxi as an example, and verified the theory model.

The main theoretical contributions of this paper can be summarized in the following three points.

Firstly, this paper initially introduces business model innovation theory into the cultivation mechanism of dynamic capability. Previous literature which develops dynamic capability theory often consists of two theoretical aspects: resource-based view and capability theory, which are greatly improving and enriching dynamic capability theory. Unlike these two aspects, this paper explores and develops the relational mechanism effect of business model innovation on dynamic capability and develops the dynamic cycle between the business model innovation and the cultivation of dynamic capabilities. Secondly, this paper centers on the new era of digital platform as the specific research context which is full of dynamic and turbulent environment. This new form of economy is largely different from traditional economy both in business model innovation and in cultivation of dynamic capabilities. Thirdly, this paper employs DiDi taxi as an exploratory case study, which represents a wholly new way to develop business model and dynamic capabilities under the complex and turbulent environment. Consequently, this paper qualitatively elaborates the proposed theoretical model of the relationship between business model innovation and dynamic capabilities, which expands the aspects of investigating the relationship between the two.

In addition, from practical aspect, this paper guides enterprises, especially platform enterprises, toward combining business model innovation with dynamic capabilities and taking various measures to ensure the success of business model innovation.

\section{Data Availability}

This research strived to use a variety of sources to collect data, mainly including the following channels: (1) enterprise archives, such as enterprise journals, work summaries, internal rules and regulations, and enterprise annual reports; (2) official website of DiDi; (3) media reports; (4) publications of third-party research institutions. Data sources and codes are shown in Table 2 in the article. The data used to support the findings of this study are available from the corresponding authors upon request.

\section{Conflicts of Interest}

The authors declare that they have no conflicts of interest.

\section{Acknowledgments}

This work was supported by the Social Science Foundation of Fujian (Grant nos. FJ2018B062 and FJ2019B101) and Fujian Provincial Department of Science and Technology, Soft Science Research Plan Project (Grant nos. 2019R0093 and 2019R0094).

\section{References}

[1] J. Magretta, "Why business models matter," Harvard Business Review, vol. 80, no. 5, pp. 86-92, 2002.

[2] M. A. Rappa, "The utility business model and the future of computing services," IBM Systems Journal, vol. 43, no. 1, pp. 32-42, 2004.

[3] A. Osterwalder, Y. Pigneur, and C. L. Tucci, "Clarifying business models: origins, present, and future of the concept," Communications of the Association for Information Systems, vol. 16, no. 1, pp. 1-25, 2005.

[4] C. Zott, R. Amit, and L. Massa, "The business model: recent developments and future research," Journal of Management, vol. 37, no. 4, pp. 1019-1042, 2011.

[5] M. Morris, M. Schindehutte, and J. Allen, “The entrepreneur's business model: toward a unified perspective," Journal of Business Research, vol. 58, no. 6, pp. 726-735, 2005.

[6] D. J. Teece, G. Pisano, and A. Shuen, "Dynamic capabilities and strategic management," Strategic Management Journal, vol. 18, no. 7, pp. 509-533, 1997.

[7] D. J. Teece, Managing Intellectual Capital: Organizational, Strategic, and Policy Dimensions, Oxford University Press, Oxford, U.K, 2002.

[8] M. Zollo and S. G. Winter, "Deliberate learning and the evolution of dynamic capabilities," Organization Science, vol. 13, no. 3, pp. 339-351, 2002.

[9] C. L. Wang and P. K. Ahmed, "Dynamic capabilities: a review and research agenda," International Journal of Management Reviews, vol. 9, no. 1, pp. 31-51, 2007.

[10] D. J. Teece, "Explicating dynamic capabilities: the nature and microfoundations of (sustainable) enterprise performance," Strategic Management Journal, vol. 28, no. 13, pp. 1319-1350, 2007.

[11] P. A. Pavlou and O. A. El Sawy, "Understanding the elusive black box of dynamic capabilities," Decision Sciences, vol. 42, no. 1, pp. 239-273, 2011.

[12] P. Lin, "Measurement and function of dynamic capabilities: empirical data from Chinese enterprises," Journal of Central South University: Social Science Edition, vol. 04, pp. 86-93, 2009.

[13] D. M. D. Moraes, "The internet of things - the value is the customer experience," Appliance Design, vol. 64, no. 7, pp. 25-26, 2016.

[14] J. T. Gourville, "Eager sellers and stony buyers: understanding the psychology of new-product adoption," Harvard Business Review, vol. 84, no. 6, pp. 98-145, 2006.

[15] A. Najmei, "Dynamic Business Model Innovation: An Analytical Archetype," in Proceedings of the 2011 3rd International Conference on Information and Financial Engineering IPEDR, pp. 165-171, Shanghai, China, August 2011.

[16] D. J. Teece, "Business models and dynamic capabilities," Long Range Planning, vol. 51, no. 1, pp. 40-49, 2018.

[17] K. S. R. Warner and M. Wäger, "Building dynamic capabilities for digital transformation: an ongoing process of strategic renewal," Long Range Planning, vol. 52, no. 3, pp. 326-349, 2018.

[18] K. M. Eisenhardt and M. E. Graebner, "Theory building from cases: opportunities and challenges," Academy of Management Journal, vol. 50, no. 1, pp. 25-32, 2007. 